\title{
A Summary of the Application of Artificial Intelligence in Music Education
}

\author{
Jin Zhang ${ }^{1, a}$ and Jiawei Wan ${ }^{1, b}$
}

\author{
${ }^{I}$ School of Music, Nanchang Institute of Technology; Nanchang, Jiangxi, China \\ zhangjin@nut.edu.cn, ${ }^{b}$ wanjiawei@nut.edu.cn
}

\begin{abstract}
With the development of modern science and technology, the application of artificial intelligence in music education is more and more extensive, which is beneficial to the development of music education in China. The application of artificial intelligence in music education has broken the traditional music education model, especially the application of computer music system and high intelligent music software in music education, which has greatly improved the quality of music teaching and expanded the music teaching model. This paper is a summary of the research achievements of Cao Meng, Zou Mengyu, Deng Yue and Yuan Quan.
\end{abstract}

Keywords: artificial intelligence, musicology, education

\section{INTRODUCTION}

Artificial intelligence was first used in music teaching in the 1960 s, when it was only applied to musical keyboards to form a new musical instrument. The instrument can store the Timbre of a variety of instruments, and has the advantage of being able to play anywhere at any time, changing the Timbre of the instrument as it is played, and being small and portable. But at that time, the development and understanding of artificial intelligence technology were not deep enough, and most music teachers are not familiar with this new intelligent musical instrument, and have no idea that it will be widely used in the future development of music teaching. Therefore, although this kind of musical instrument is used in the music teaching, but has not caused the very big attention, many schools' music teaching still in the traditional teaching pattern [2]. Therefore, the application of artificial intelligence technology in the early music teaching has not played a great role.

\section{ARTIFICIAL INTELLIGENCE SYSTEM TEACHING ENRICHES THE TEACHING MODE OF TEACHERS}

The application of artificial intelligence system equipment can arouse students' interest in learning music, which is more an innovation aimed at traditional students' teaching. Through the use of artificial intelligence system, diversified music education has been carried out. In the music education activities of primary and middle school students, artificial intelligence system is used to enhance students' enthusiasm and initiative, which is beneficial to students' active learning and absorption of knowledge. In College non-professional Music Education, the classroom teaching content is made into the teaching courseware of artificial intelligence system, which helps to guide students to learn new knowledge actively and actively, allow students to participate in the artificial intelligence system under the teaching of music learning, so as to achieve the greatest absorption of music knowledge.

\section{IMPROVE THE INITIATIVE OF STUDENTS' LEARNING AND ENHANCE THE TEACHING EFFECT}

Because of its strong integration, artificial intelligence system can aggregate various media data, such as image, sound, video and so on. Information is processed and interacted to make full use of it. Through artificial intelligence system assistance, teaching time can be further shortened. Because time and space are not limited, it can transform the illusory things into reality, and abstract things into concrete things, which can promote the teacher's expression to the music education classroom, attract students' attention, and achieve sensory coordination [4].

\section{APPLICATION OF ARTIFICIAL INTELLIGENCE MUSIC SOFTWARE IN MUSIC EDUCATION}

With the development of computer technology, a lot of intelligent music software related to computer technology has appeared, which makes the original music task that depends on synthesizer or music worker to process and edit all be done by computer, thus improving the processing ability of music data and enlarging the range of music information. This kind of music software is very powerful, users can be free to edit, modify, record and play, and process all kinds of music elements with artificial intelligence. Now, this new type of music system has been applied in music teaching, which has greatly promoted the development of music teaching. After the introduction of this music system in music education, teachers and students also have a platform for communication and interaction in teaching. The teaching method of music teaching has also changed a lot. First, students can use the new music system to feel the music and experience the charm of each note. Second, students can practice whatever music the teacher teaches in the class. Through actual playing, the students can better understand the music knowledge that the teacher talks about, understand the characteristics and functions of each music element. Finally, the teacher can also use this method 
to perform ensemble with the students and understand each student's knowledge of music by listening to the students' performance. For example, in a music class, the teacher might play a question and then ask the student to play an answer, or the teacher might play a piece of music and then ask the student to repeat it or to re-create it. In this way, not only students can better experience music, students and teachers can also communicate and interact. In the classroom, students will change from a passive role to an active one, no longer only listen to the teacher's explanation, but also can experience and understand the music through the artificial intelligence system, understand the music, and experience the music that can't be experienced by the teacher. Through the use of this artificial intelligence software, students can learn more about the characteristics and functions of each music element, and understand how these music elements are built in the process of construction [2].

\section{ARTIFICIAL INTELLIGENCE TECHNOLOGY PROMOTES NETWORK EDUCATION OF MUSIC EDUCATION}

The use of artificial intelligence technology can also promote the learning and application of music teaching to the network. The use of intelligent instruments and software in music teaching has allowed the addition of some new music courses and music teaching methods in music education. In music teaching, the courses of composition, instrumental, analytical work and so on all adopt intelligent teaching methods, so that students can play, listen and modify at any time while creating, which improves the efficiency of students' creation. Students can better understand the characteristics and functions of music knowledge, music symbols and musical elements in the network system, which allows students to have a better music experience during the learning process. Through the use of artificial intelligence in music teaching, the networked teaching mode of music classroom has been more widely promoted. In the classroom, teachers and students can communicate music more smoothly, and music exchanges between students are more frequent. In the classroom, teachers and students can make full use of the advantages of online learning, strengthen interaction, and continuously improve the quality of music classroom teaching. The use of networked learning has brought about two major changes in music education: on the one hand, it has impacted on traditional music concepts; on the other hand, it has changed the way music information is acquired. Due to the characteristics of the Internet itself, music teaching has gone out of the campus and has moved to the world, realizing the teaching of music teaching. Through the network, teachers and students can access music information more conveniently. Not only can they get the music information they want quickly, but they can also get a lot of other music information, and the information is more extensive. However, due to the large and complicated information of the network, students who study through the network may not be able to achieve the goal of learning. Therefore, schools should set up online music learning courses, so that teachers can use the network to get more music textbooks, and also enable teachers to explain various music information to students through the network, and deepen students' understanding of music. Therefore, the Internet has become an important part of school music teaching. The network is extended to the music classroom, which expands the students' horizons and expands the students from the original book to the whole world. Students can not only get more music information and knowledge from the Internet, but also post their music works on the Internet, so that more people can see and hear them, and integrate themselves into the world music environment, thus to constantly learn and enrich themselves [3].

\section{THE DEVELOPMENT TREND OF ARTIFICIAL INTELLIGENCE IN MUSIC EDUCATION}

In the Future Society, the application of artificial intelligence in music education may help students reveal their problems in the process of music learning, covering a variety of rich music resources, and providing students with the music learning resources they need, to improve the efficiency of music education and learning. For example, in the process of piano education for children, Artificial Intelligence can further enable learners to experience the magic of the organic integration of music and science and technology by helping learners find better teacher resources and relying on the web platform provided by artificial intelligence to obtain high-level music instruction. In addition, the future artificial intelligence may also realize the effective interpretation of music teacher's language and emotion, and can follow the music teacher's humanized teaching method, and further make the music presented by the machine become wider and deeper. It should be noted that the future application of artificial intelligence in music education may also have some limitations: First, it comes from the limitations of the particularity of music education. The application of artificial intelligence in music education mainly plays a supporting role, such as the ability to teach the basic theories of music teaching, such as pitch, tone, size, and arpeggio, but for the emotional aspects of music teaching, such as music emotion, music content expression, tone and so on, artificial intelligence has certain limitations. Secondly, it comes from the limitations of industry recognition. Artificial intelligence technology in music education still needs to be widely recognized and accepted by the industry, most people in the industry believe that music is need to be perceived, machines in the experience of a variety of complex human emotions there are certain limitations [2].

\section{CONCLUSION}

With the continuous development of artificial intelligence, it has been widely infiltrated and promoted in the field of music education, realizing the organic integration and interaction of music and science and technology, which has greatly promoted the development of music education in China. Therefore, China's music education and teaching workers must innovate ideas, improve the effective understanding of artificial intelligence in music education, strengthen the scientific and rational application of artificial intelligence in music education, closely follow the development trend of the application of artificial intelligence 
in music education, and actively promote the healthy and stable development of Music Education in China.

With the continuous progress of society, the application of artificial intelligence system in student education will become a key factor in deepening the reform of pre-school curriculum and optimizing educational means. Modern information technology and artificial intelligence system teaching methods can combine all kinds of educational information with teachers' teaching and students' learning, so as to achieve the best teaching results. As an educator, efforts should be made to develop, explore, and study how to properly use artificial intelligence systems in teaching practice. Only on the basis of following the law of education and teaching and the law of students' cognitive development, making full use of and mastering information technology as a modern means of education, constantly exploring how to integrate information technology and classroom teaching more perfectly, the application of artificial intelligence system in student teaching can be optimized. Therefore, the application of modern teaching methods is an important means to promote students' music education.

\section{ACKNOWLEDGMENT}

Fund Project: GJJ181000, "Research on IT Application and Design Based on Instrument Sound Source," 2018 Science and Technology Research Project of Jiangxi Provincial Department of Education.

\section{REFERENCES}

[1] Cao Meng, "Exploring the Application Value of Artificial Intelligence System in Music Education in Primary and Middle Schools," Northern Music, 2019, Issue 11, 100-105. (In Chinese)

[2] Zou Mengyu, "Artificial Intelligence and Its Application in Music Education," Northern Music, 2018, Issue 15, 31-37. (In Chinese)

[3] Deng Yue, "Talking about the Application of Artificial Intelligence in Music Education of Secondary Vocational Schools," HOME FOR YOU, 2018, Issue 12, 50-51. (In Chinese)

[4] Yuan Quan, " Applied Research of Artificial Intelligence in Music Education," Northern Music, 2019, Issue 17, 38-44. (In Chinese) 